\title{
Recent California Water Year Precipitation Deficits: A 440-Year Perspective*
}

\author{
HENRY F. DIAZ \\ NOAA/ESRL/Cooperative Institute for Research in Environmental Sciences, University of Colorado, Boulder, Colorado \\ EUGENE R. WAHL \\ Paleoclimatology Group, NOAA/National Centers for Environmental Information, Boulder, Colorado
}

(Manuscript received 12 November 2014, in final form 18 February 2015)

\begin{abstract}
An analysis of the October 2013-September 2014 precipitation in the western United States and in particular over the California-Nevada region suggests this anomalously dry season, while extreme, is not unprecedented in comparison with the approximately 120-yr-long instrumental record of water year (WY; October-September) totals and in comparison with a 407-yr WY precipitation reconstruction dating back to 1571. Over this longer period, nine other years are known or estimated to have been nearly as dry or drier than WY 2014. The 3-yr deficit for WYs 2012-14, which in California exceeded the annual mean precipitation, is more extreme but also not unprecedented, occurring three other times over the past approximate 440 years in the reconstruction. WY precipitation has also been deficient on average for the past 14 years, and such a run of predominantly dry WYs is also a rare occurrence in the authors' merged reconstructed plus instrumental period record.
\end{abstract}

\section{Introduction}

The October 2013-September 2014 water year (WY) precipitation in the western United States, particularly in California, was much below the long-term average. Parts of California received less than $25 \%$ of normal precipitation in the 2013/14 WY, as shown in Fig. 1 (top). (Hereafter, WYs are noted by the calendar year of the January-September period included in them.) A time series of October-September precipitation for California is shown in the bottom panel of Fig. 1, which shows that this past WY was among the top three driest WYs on record. We assess how uncommon this most recent WY climate anomaly has been by addressing two questions: 1) How unusual is the $2014 \mathrm{WY}$ total for the California-Nevada region as well as for the nominal western states with respect to the 118-yr instrumental

\footnotetext{
* Supplemental information related to this paper is available at the Journals Online website: http://dx.doi.org/10.1175/JCLI-D-1400774.s1.

Corresponding author address: Henry F. Diaz, NOAA/ESRL/ CIRES, 325 Broadway, Boulder, CO 80305.

E-mail: henry.f.diaz@noaa.gov
}

record and a longer paleoclimate reconstruction dating back to 1571? 2) Are the characteristics of the predominant atmospheric circulation patterns consistent with past extremely dry seasons or are there features that differ from previous dry episodes? In addition, as the exceptionally dry WY comes after the occurrence of two previously significantly dry WYs, particularly in California, we also assess how rare is the occurrence of such three consecutively dry years as described below.

Consistent with many previous studies (Namias 1978; Cayan and Peterson 1989; Cayan et al. 1998; Wang et al. 2014), the midtropospheric flow for WY 2014 depicted in Fig. 2 (top) in the form of geopotential height (GPH) anomalies at the $700-\mathrm{mb}$ level $(\sim 3 \mathrm{~km} ; 1 \mathrm{mb}=1 \mathrm{hPa})$ exhibits strong ridging to the west and northwest of the continent. As noted, the 2014 WY occurred after two very dry WYs in California, so the cumulative deficit for the last three seasons was over $100 \%$ of the annual mean precipitation for the state. The corresponding 700-mb GPH anomaly for the last 3-yr period is shown in the bottom panel of Fig. 2, which illustrates the persistent nature of the anomalous high pressure ridge in the North Pacific. In the following sections, we show the anomalous precipitation patterns for a selection of the driest-ranked 


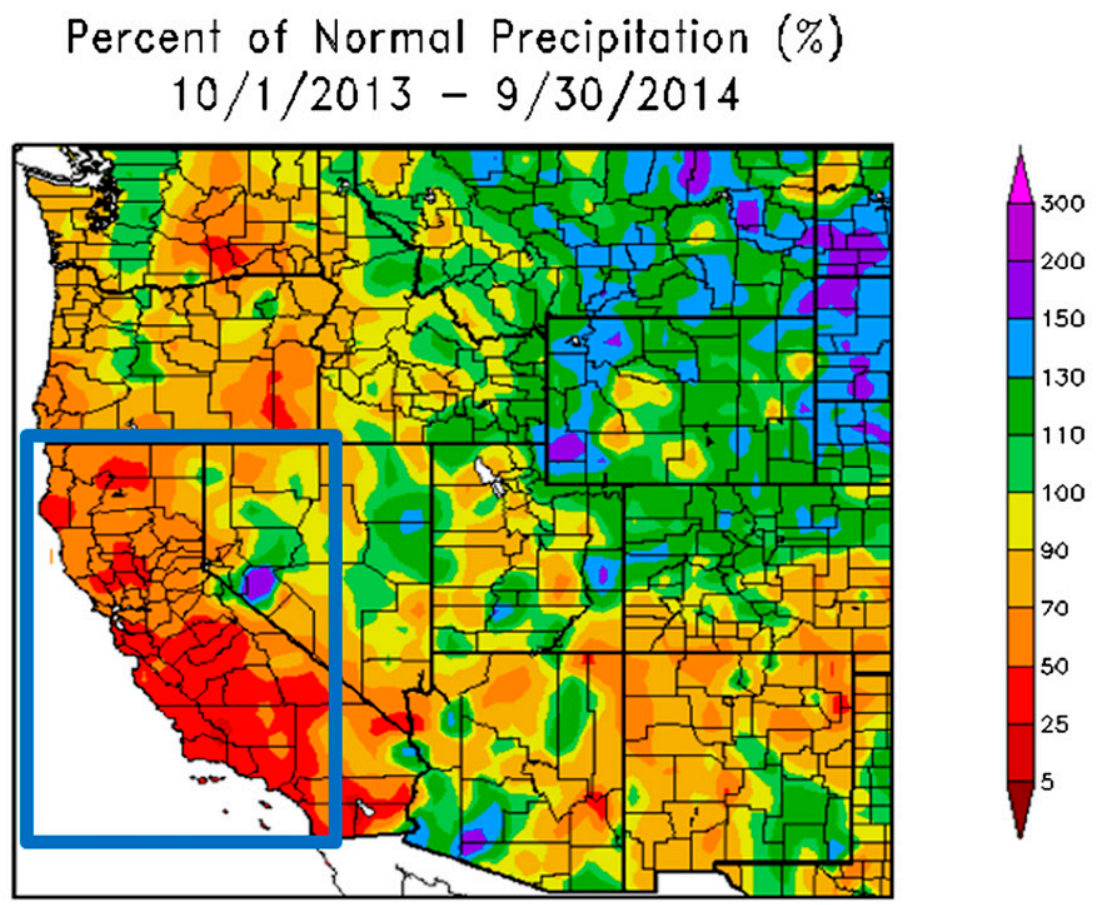

Generated 10/5/2014 ot HPRCC using provisional dato.

Reqional Climate Centers

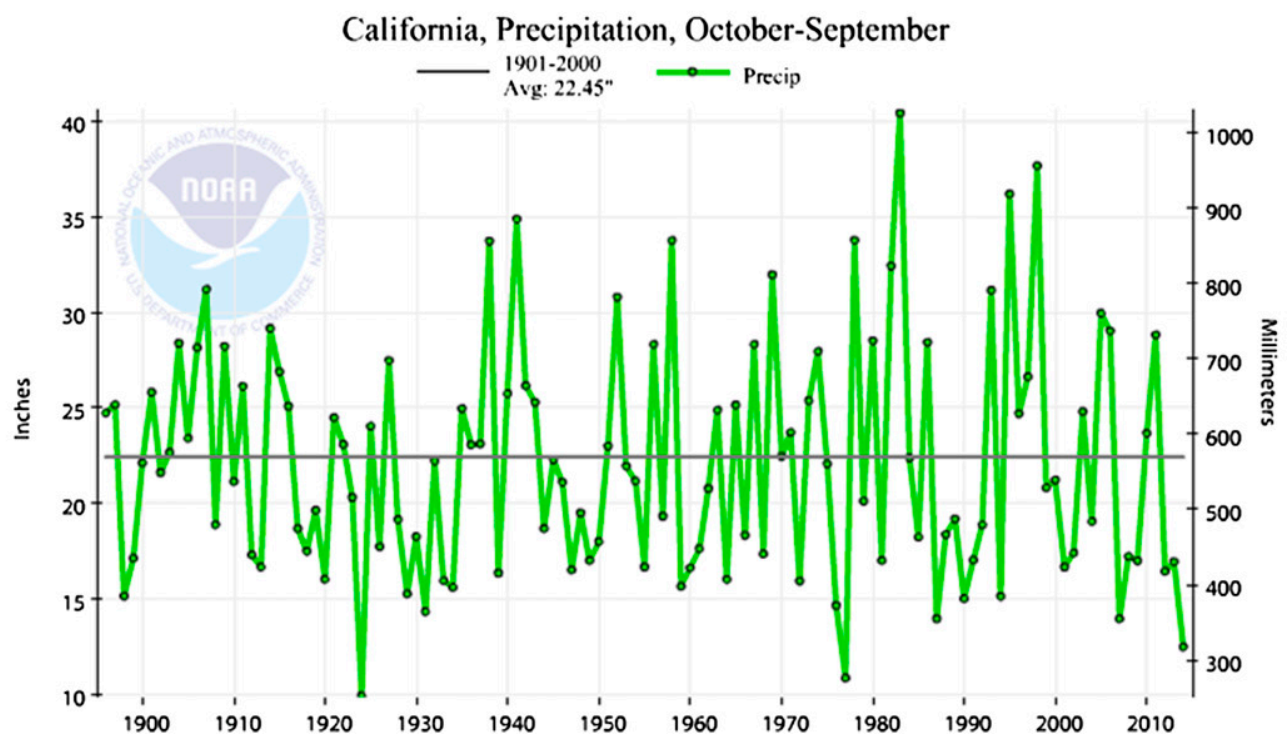

FIG. 1. (top) Percent of normal precipitation for the period 1 Oct 2013-30 Sep 2014 for the western United States. The blue rectangle denotes area of the gridded reconstruction values used in this study. See text for details. (bottom) Time series of October-September precipitation for California (1895/96-2013/14). Sources are the High Plains Regional Climate Center, Lincoln, Nebraska for (top; downloaded from website http://www.hprcc.unl.edu/) and the NCEI, Asheville, North Carolina (Vose et al. 2014) for (bottom).

WY reconstructions for the western United States and examine differences and similarities among those years compared to the recent dry period. While our focus here is largely on the precipitation side of the moisture balance relationship, we will also show that related measures of drought conditions that include the effect of temperature on soil moisture and related drought indices [Palmer drought severity index (PDSI) and 
NCEP/NCAR Reanalysis

700mb Geopotential Height (m) Composite Anomaly 1981-2010 climo

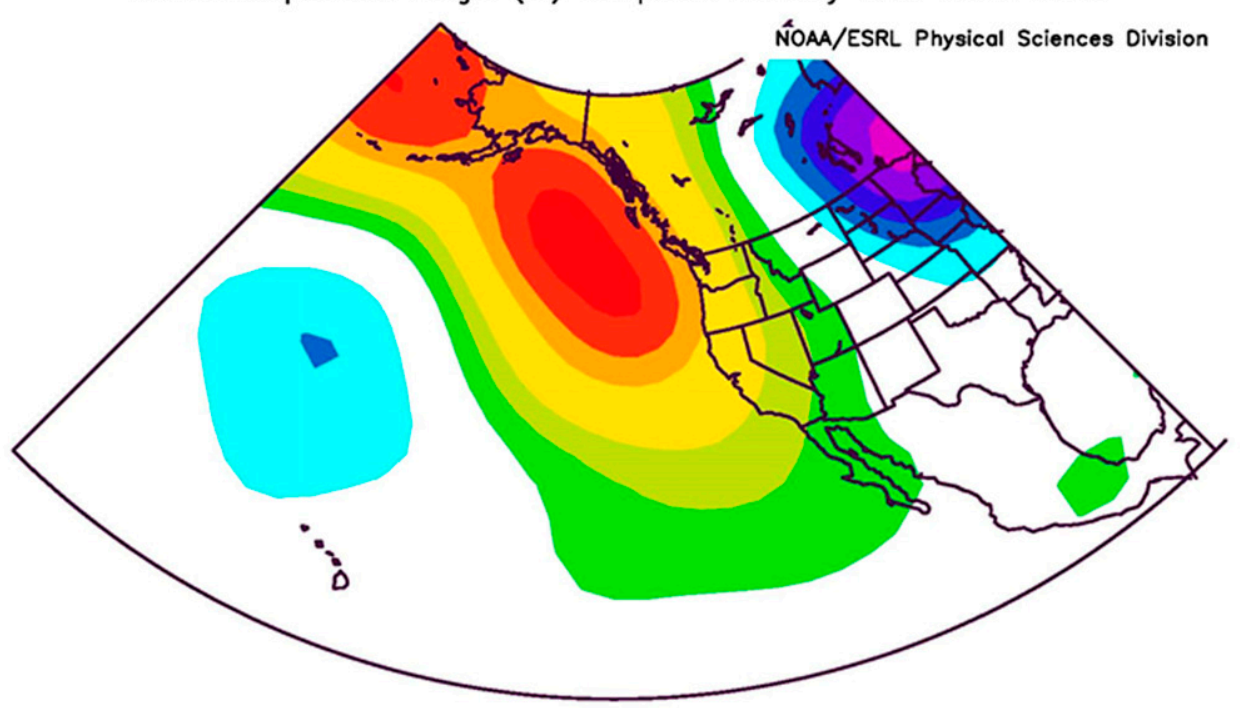

Oct to Sep: 2014

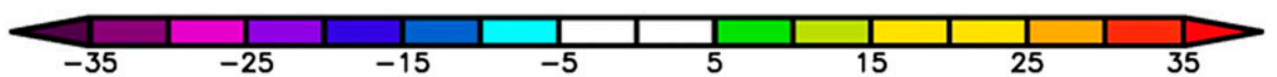

NCEP/NCAR Reanalysis

700mb Geopotential Height (m) Composite Anomaly 1981-2010 climo

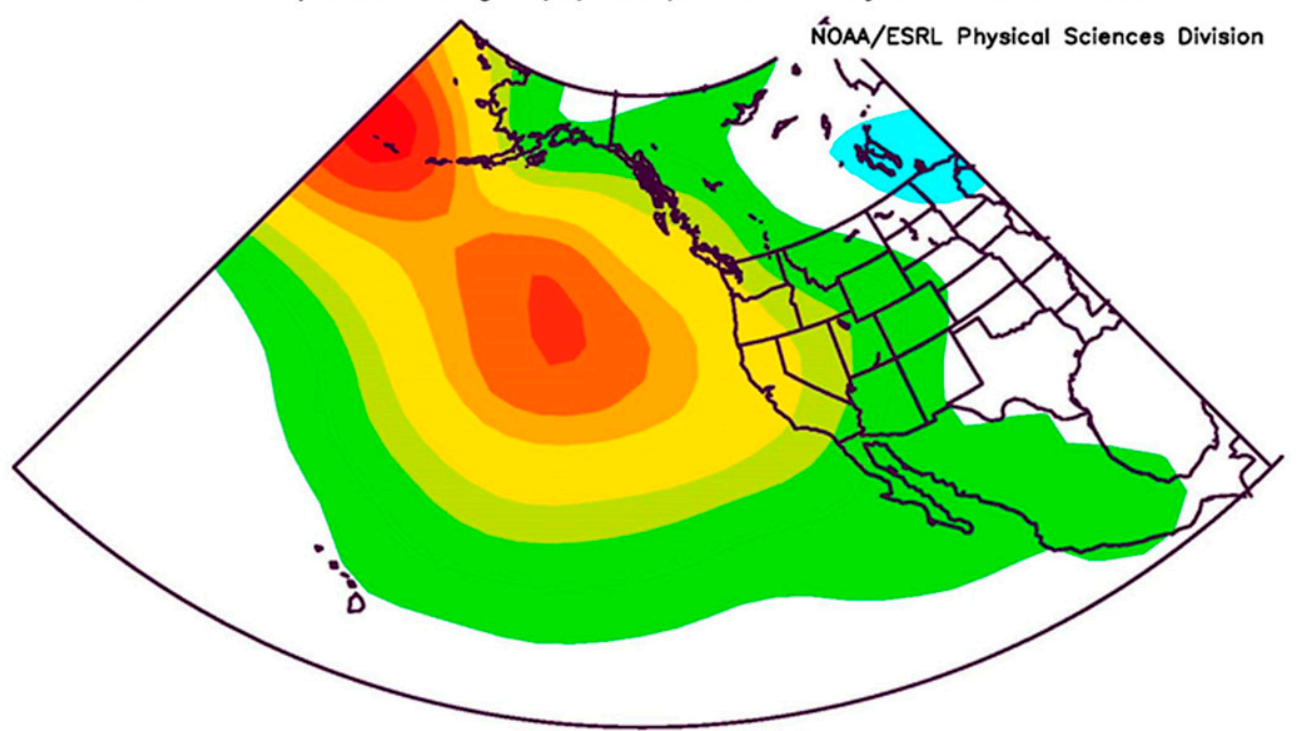

Oct to Sep: 2012 to 2014

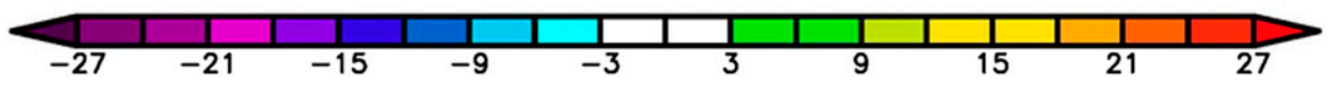

FIG. 2. Geopotential height anomaly at $700 \mathrm{mb}$ for the periods (top) October 2013-September 2014 and (bottom) October 2011-September 2014. 
NOAA/NCDC Climate Division Standardized Precipitotion Anomalies Oct to Sep 1898-99 Versus 1950-1995 Longterm Averoge

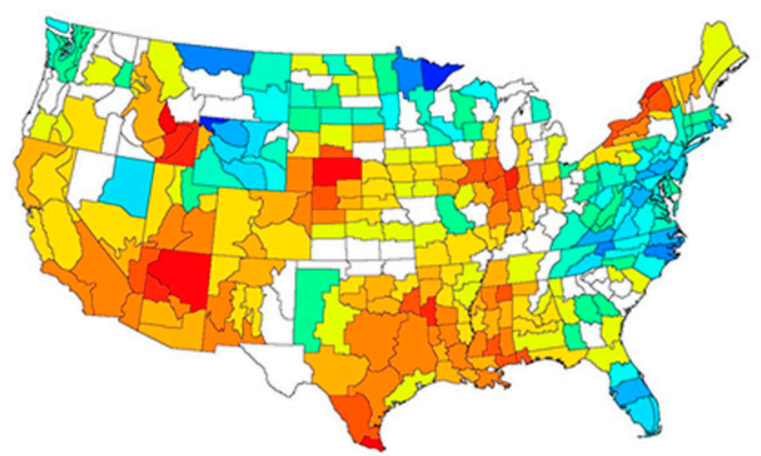

NOMVESRL PSO and CIRES-CU

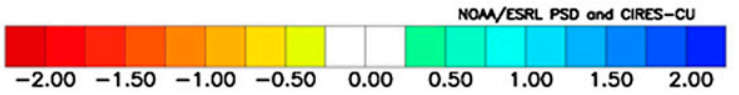

NOAA/NCDC Climate Division Standardized Precipitotion Anomalies Oct to Sep 1933-34 Versus 1950-1995 Longterm Averoge

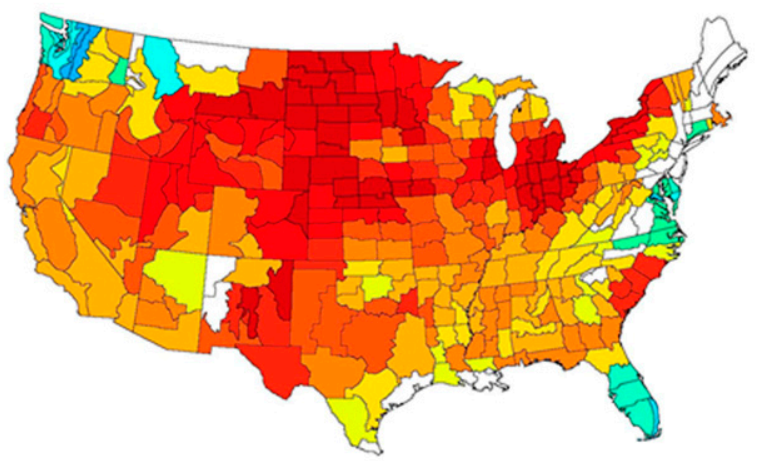

NOWESRL PSO and CIRES-CU

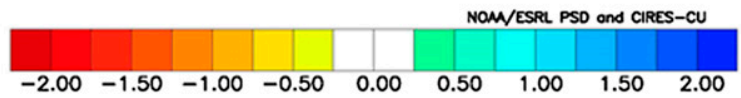

NOAA/NCDC Climate Division Standardized Precipitation Anomalies Oct to Sep 1923-24 Versus 1950-1995 Longterm Averoge

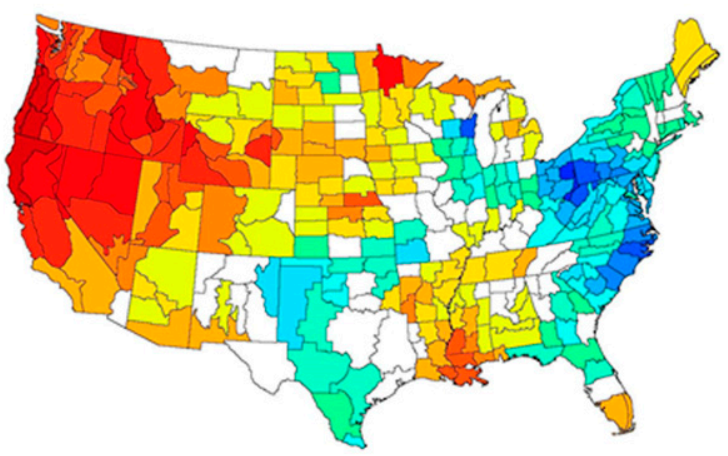

NOMVESRL PSO and CIRES-CU

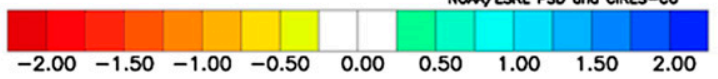

NOAA/NCDC Climate Division Stondardized Precipitotion Anomalies Oct to Sep 1976-77 Versus 1950-1995 Longterm Average

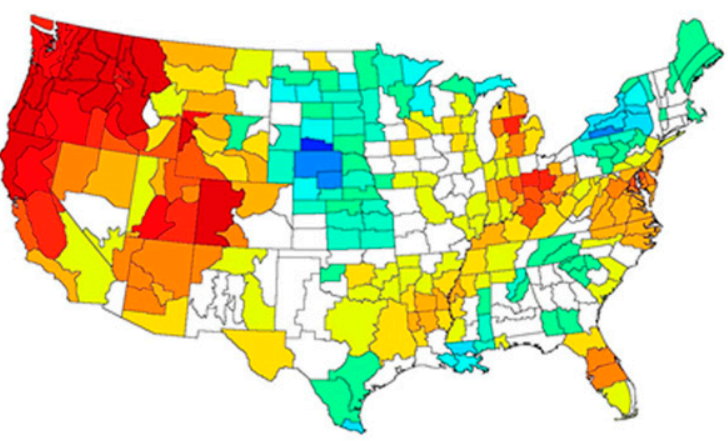

NOMVESRL PSO and CRRES-CU

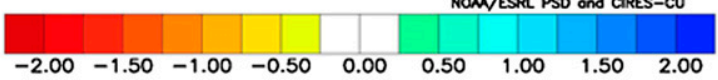

FIG. 3. Maps of standardized precipitation anomalies for the months October-September of analog water years (top left) 1898/99, (top right) 1923/24, (bottom left) 1933/34, and (bottom right) 1976/77.

standardized precipitation-evapotranspiration index (SPEI)] also point to the recent period as being highly unusual if not unprecedented (cf. Griffin and Anchukaitis 2014).

\section{Reconstruction methodology, data, and evaluation}

The truncated EOF-principal components spatial regression (TEOF-PCSR) methodology used to assess preinstrumental climate in western North America is described and evaluated in detail in Wahl and Smerdon (2012; cf. supplemental material therein) and was also used to evaluate late winter temperature responses in the region to large tropical volcanic eruptions (Wahl et al. 2014). Here we employ this method to reconstruct gridded WY precipitation for the continental United States west of $95^{\circ} \mathrm{W}$ and then extract the WY mean for California and adjoining western Nevada (CANV; west of $116.5^{\circ} \mathrm{W}$ and south of $42^{\circ} \mathrm{N}$ ) for detailed analysis. This area roughly corresponds to the "west region" monitored by the U.S. National Centers for Environmental Information (NCEI). The time series of WY precipitation for the two states together (not shown) is very close to that for California alone.

The gridded predictand calibration data are monthly precipitation values at $0.5^{\circ} \times 0.5^{\circ}$ resolution (Vose et al. 2014), annualized over the October-September WY period. The reconstruction predictors are 14 long WY 

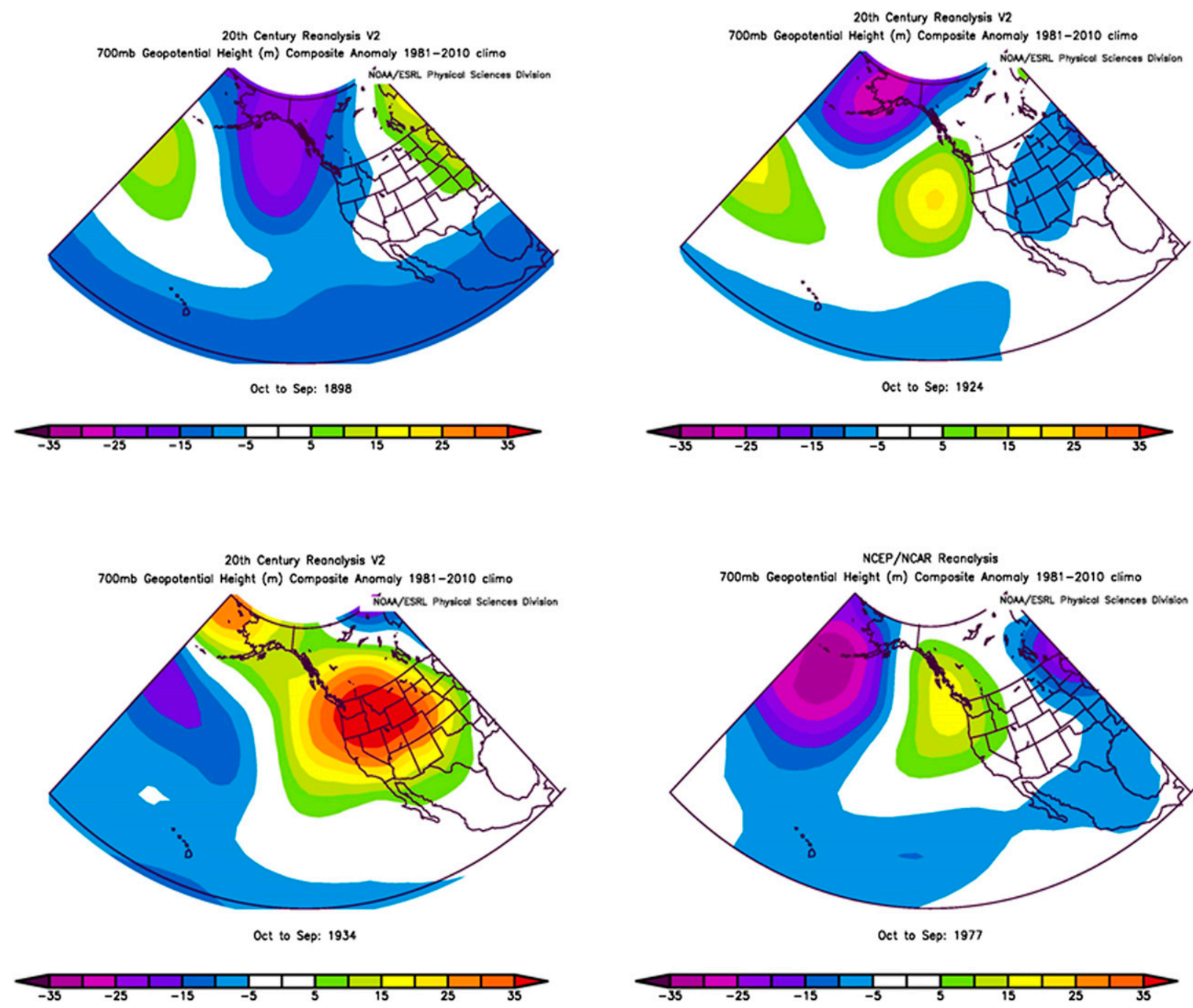

FIG. 4. As in Fig. 3, but for the corresponding 700-mb anomaly patterns. Scale is the same in each panel for comparison with the 2014 WY pattern in Fig. 2. The 1977 map is from NCEP-NCAR reanalysis data, while for the other three maps data were taken from the Twentieth Century Reanalysis dataset (Compo et al. 2011).

streamflow reconstructions within the calibration spatial domain, covering the period 1571-1977. We utilize the streamflow reconstructions as proxy predictors rather than the underlying tree-ring chronologies directly based on the fact that precipitation determines streamflow to a large degree even in the seasonally dry western United States (e.g., Graham and Hughes 2007, their Fig. 5), and relatively large basins integrate precipitation over their full domain. Thus, the streamflow reconstructions are expected to have significantly reduced the nonprecipitation information present in the original tree-ring data used to drive them that is not useful from the perspective of reconstructing spatial precipitation fields. Added confirmation of the efficacy of using the streamflow reconstructions as predictors is indicated by the absence in the CANV time series of the possible long-term memory bias identified in (at least some) long tree-ring-based precipitation reconstructions by Bunde et al. (2013), which they attribute to trees responding to local-scale soil moisture persistence along with their responses to larger-scale white-noise precipitation fluctuations (Fig. S4 of the supplemental material). It should be noted that most but not all the available streamflow time series in the region going back into the late 1500s were utilized. This was done because reconstructions for some smaller streams in the Missouri River basin along the mountains of the Front Range in Colorado are repetitive, even though they represent individual upstream basins, and therefore not all of them were included. Additional information concerning the 

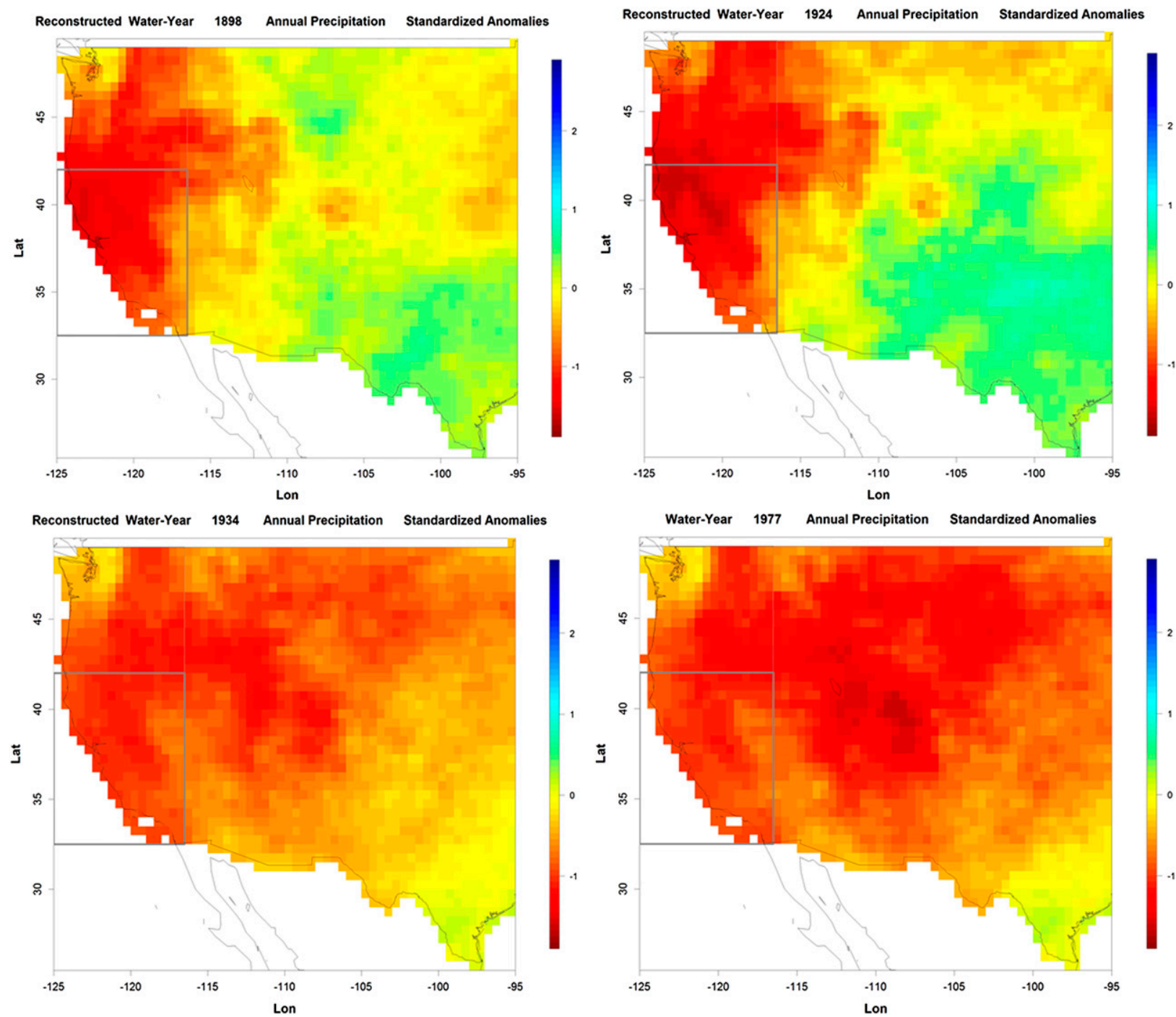

FIG. 5. Reconstructed precipitation (standardized anomalies) for water years 1897/98, 1923/24, 1933/34, and 1976/77. The gray-outlined box in southwestern corner of reconstruction area highlights the California and western Nevada subregion $\left(32.5^{\circ}-42^{\circ} \mathrm{N}, 116.5^{\circ}-125^{\circ} \mathrm{W} ;\right.$ not including ocean grid cells, as noted).

streamflow reconstructions used, along with a listing and reference information, is provided in the supplemental material.

The instrumental precipitation data were converted into standardized anomalies with regard to their 18962012 means and standard deviations, which is the form of the reconstruction values shown [with the exception of the CANV spatial mean in Figs. 9 and 10]. The singular value decomposition (SVD) was used to extract the spatial EOFs, along with their associated annual time series [principal components (PCs)] and overall weights (singular values). The streamflow data were input into the SVD analysis in their primary units [all of which were originally in or converted to acre foot per year $\left.\left(\approx 3.909 \times 10^{-5} \mathrm{~m}^{3} \mathrm{~s}^{-1}\right)\right]$, so that the relative influence of the very large river/basin flows would strongly weight in the PCs used for reconstruction.

Extensive testing of combinations of instrumental and predictor EOFs/PCs employed in the western domain spatial reconstruction (cf. Wahl and Smerdon 2012, and supplemental material therein) indicates a region of best performance centered on retaining instrumental EOFs 1-7 in conjunction with streamflow EOFs $1-3,5,7,11$, and 12. It should be noted that after seven EOFs, the instrumental data scree plot (cf. Wilks 1995) has a distinct discontinuity, which is a separate criterion for establishing an EOF retention threshold. These instrumental and predictor EOF sets were those used to 

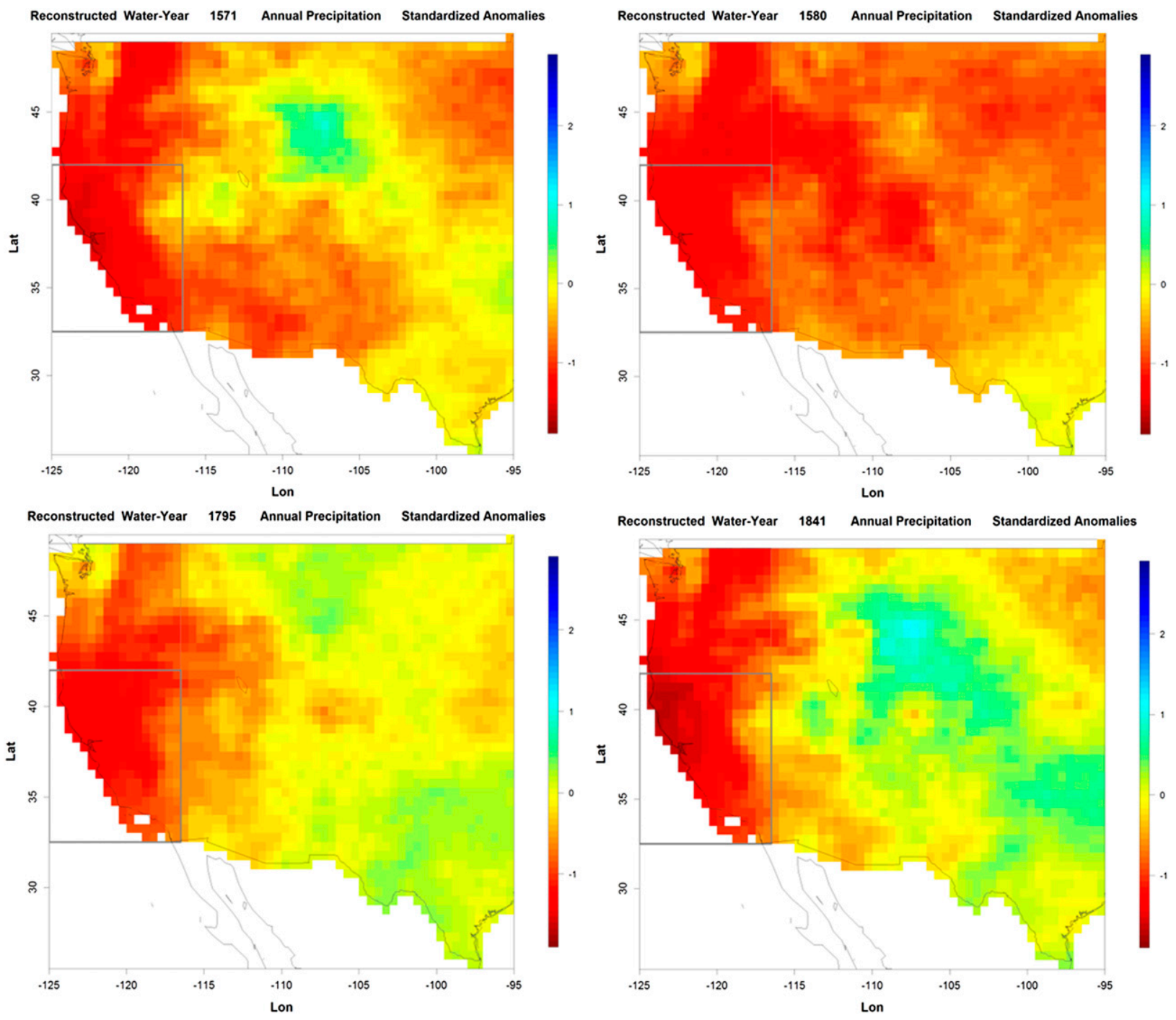

FIG. 6. As in Fig. 5, but for the analog drought years of 1571, 1580, 1795, and 1841.

determine the spatial and CANV reconstructions reported and evaluated in this paper. Once this primary decision was made, additional graphical evaluation was made using the same retained proxy EOFs with higher numbers of retained instrumental EOFs. As expected, retaining more instrumental EOFs provides spatial reconstructions that exhibit (marginally in this case) increasing skill in calibration; they are also spatially "smoother" and thus appear to be more like the full-EOF instrumental data. However, this marginally increasing calibration skill and apparent spatial smoothness actually represent artificial skill because the resulting validation metrics decline in relation to using the seven EOFs retained for the primary reconstruction. In this situation, these features represent the spatial equivalent of calibration overfitting for a single time series (Wilkes 1995; cf. Wahl and Smerdon 2012, Fig. S7 of the supplemental material).

Because the TEOF-PCSR methodology reconstructs the annual weights of regionwide EOFs, good skill is expected to be possible even in areas where the streamflow data are relatively sparse. These expectations are confirmed by the high calibration and validation skill achieved for the CANV reconstruction, even though only 2 of the 14 predictor basins (the Sacramento and Salinas Rivers) are encompassed in this subregion. The CANV mean reconstruction exhibits $\mathrm{RE}_{\mathrm{cal}}=0.83$, $\mathrm{RE}_{\mathrm{val}}=0.81$, and $\mathrm{CE}_{\mathrm{val}}=0.77$, for the 1916-77 calibration (cal) and 1896-1915 validation (val) periods. RE is the "reduction of error" statistic and CE is the "coefficient of efficiency" statistic, as commonly used in reconstruction evaluation. Corresponding statistics for 

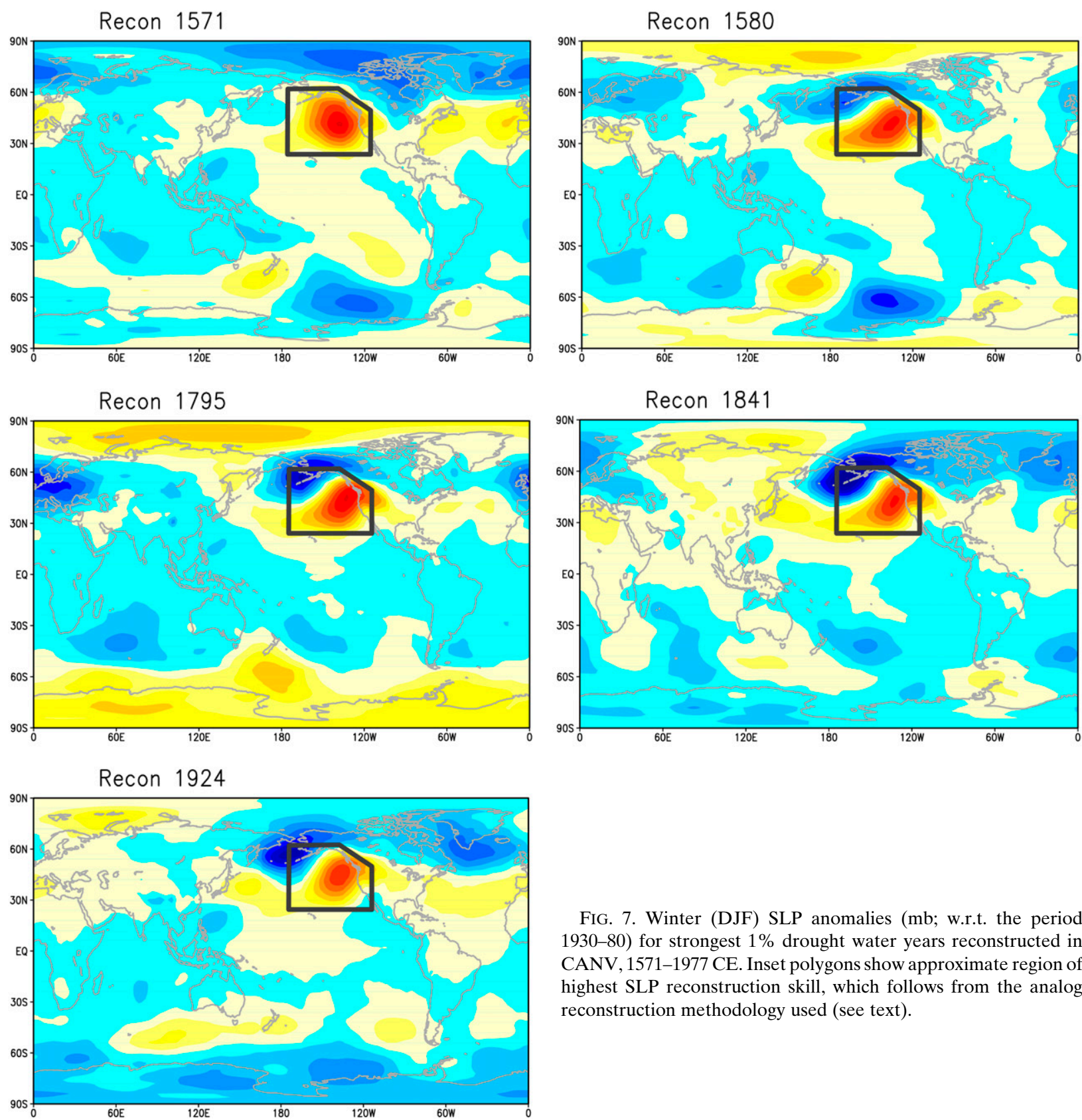

FIG. 7. Winter (DJF) SLP anomalies (mb; w.r.t. the period 1930-80) for strongest $1 \%$ drought water years reconstructed in CANV, 1571-1977 CE. Inset polygons show approximate region of highest SLP reconstruction skill, which follows from the analog reconstruction methodology used (see text).

instrumental observations spatially smoothed to same number of EOFs retained in the reconstruction are $\mathrm{RE}_{\mathrm{cal}}=0.80, \mathrm{RE}_{\mathrm{val}}=0.72$, and $\mathrm{CE}_{\mathrm{val}}=0.64$. The higher values observed using the unsmoothed instrumental data are due to relatively greater excursions exhibited by the smoothed regional time series in a number of individual years relative to the unsmoothed time series (see Fig. 9). Spatial reconstruction skill measures for the CANV region (i.e., including each grid cell in the statistic

calculations individually) are $\mathrm{RE}_{\mathrm{cal}}=0.58, \mathrm{RE}_{\mathrm{val}}=0.53$, and $\mathrm{CE}_{\mathrm{val}}=0.46$ for unsmoothed instrumental data and $\mathrm{RE}_{\mathrm{cal}}=0.71, \mathrm{RE}_{\mathrm{val}}=0.63$, and $\mathrm{CE}_{\mathrm{val}}=0.56$ for spatially smoothed instrumental observations.

Goodness of fit and residual evaluations for the CANV regional time series are shown in Figs. S1-S3 of the supplemental material. The goodness of fit performance of the reconstructions indicates strong, linear tracking of the corresponding observations (Fig. S1), and the evaluation 


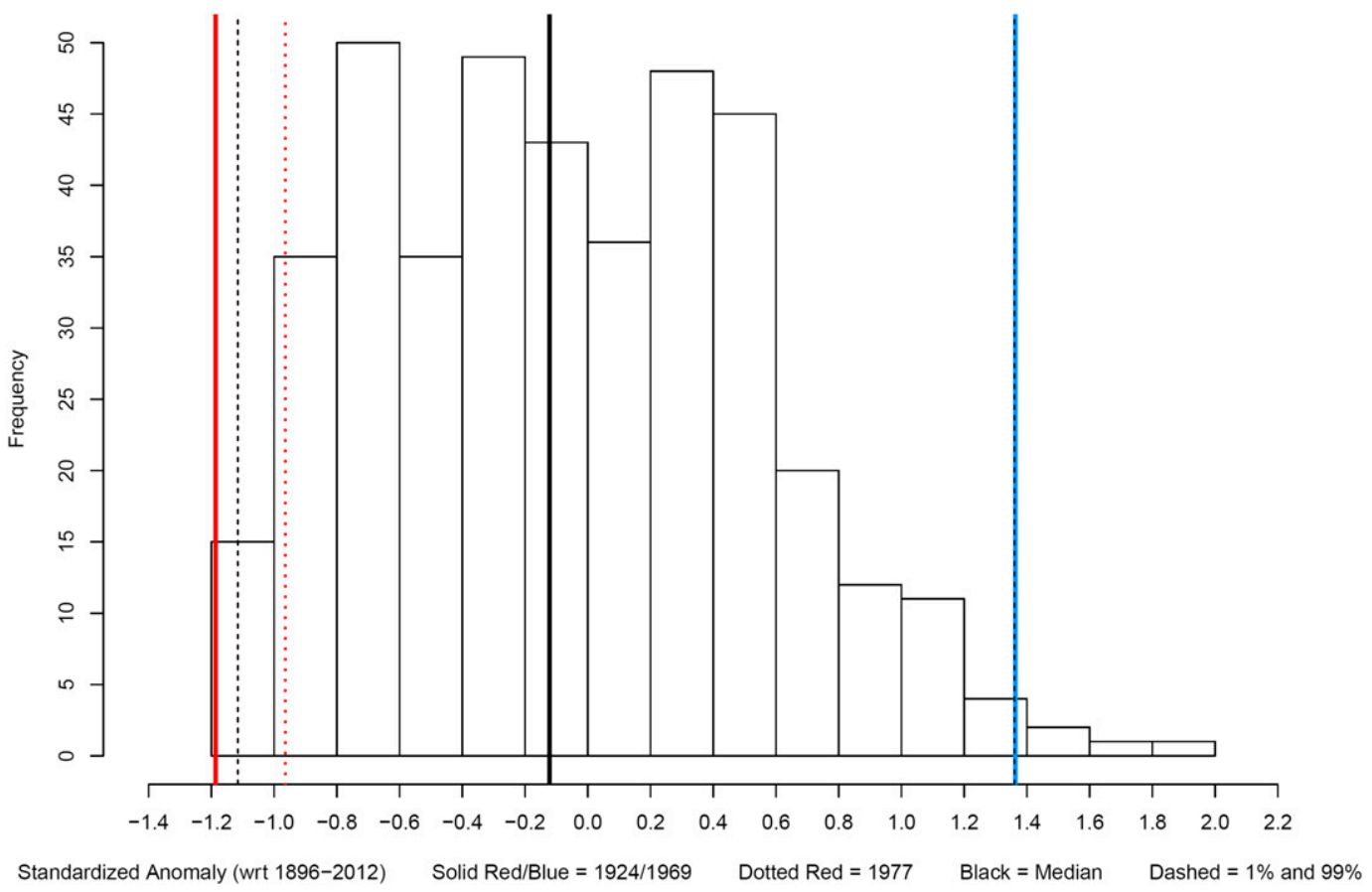

FIG. 8. Histogram of standardized water year anomaly values for the full period of the precipitation reconstructions (1571-1977) in CANV. For comparison, reconstructed WY 1924 (WY 1977) is shown as the solid (dotted) red line, and reconstructed WY 1969 is shown as the solid blue line.

of the residuals does not show indication of heteroskedasticity versus the reconstruction fit (Fig. S2) or temporal first-order autoregessive (AR1) autocorrelation (Fig. S3). An alternate test of the reconstruction using PCs of tree-ring data directly as predictors was evaluated, which did not show validation skill to reconstruct spatial precipitation patterns in the western continental United States (see supplemental material).

\section{Historical perspective of recent conditions}

How does 2014 compare to previous dry years instrumental record? The driest WY on record for the western United States as whole was in 1977 (Dettinger et al. 1998). That WY is the second driest on record for California: just behind 1924, with the most recent WY season coming in as third driest (Fig. 1, bottom). Two other very dry WYs are selected here for comparison: 1898 and 1934. Figure 3 (top) shows maps of standardized precipitation for each of these four years and Fig. 4 shows the corresponding 700-mb GPH anomaly field taken from the Twentieth Century Reanalysis version 2 dataset (Compo et al. 2011). Again, as expected, the atmospheric circulation pattern associated with these severe western drought years exhibits strong anomalous ridging over North America and the eastern North Pacific, which leads to a blocking of moisture-bearing westerly disturbances that are deflected northward toward Alaska (Fig. 4). An apparent exception is the 1898 WY map (Fig. 4, top-left panel) for which there is no obvious ridge positioned along or near the west coast of North America.

The same four years $(1898,1924,1934$, and 1977) are included in the reconstruction period and are similarly extremely dry in the precipitation reconstructions (see Fig. 9). Comparable spatial maps of reconstructed WY

TABLE 1. Standardized precipitation anomalies averaged over California and western Nevada for the nine driest water years during period 1571-1977, as reconstructed from 14 streamflow reconstructions across the west region. In the 10th rank, the reconstructed value for WY 1977 is shown for comparison; note that the 1977 reconstruction represents a random undershoot in relation to the instrumental target (cf. Fig. 9).

\begin{tabular}{rcr}
\hline \hline Rank & Year $(\mathrm{CE})$ & Std value \\
\hline 1 & 1580 & -1.186 \\
2 & 1924 & -1.186 \\
3 & 1841 & -1.141 \\
4 & 1795 & -1.122 \\
5 & 1571 & -1.116 \\
6 & 1898 & -1.108 \\
7 & 1721 & -1.101 \\
8 & 1655 & -1.067 \\
9 & 1931 & -1.046 \\
10 & 1977 & -0.964 \\
\hline
\end{tabular}




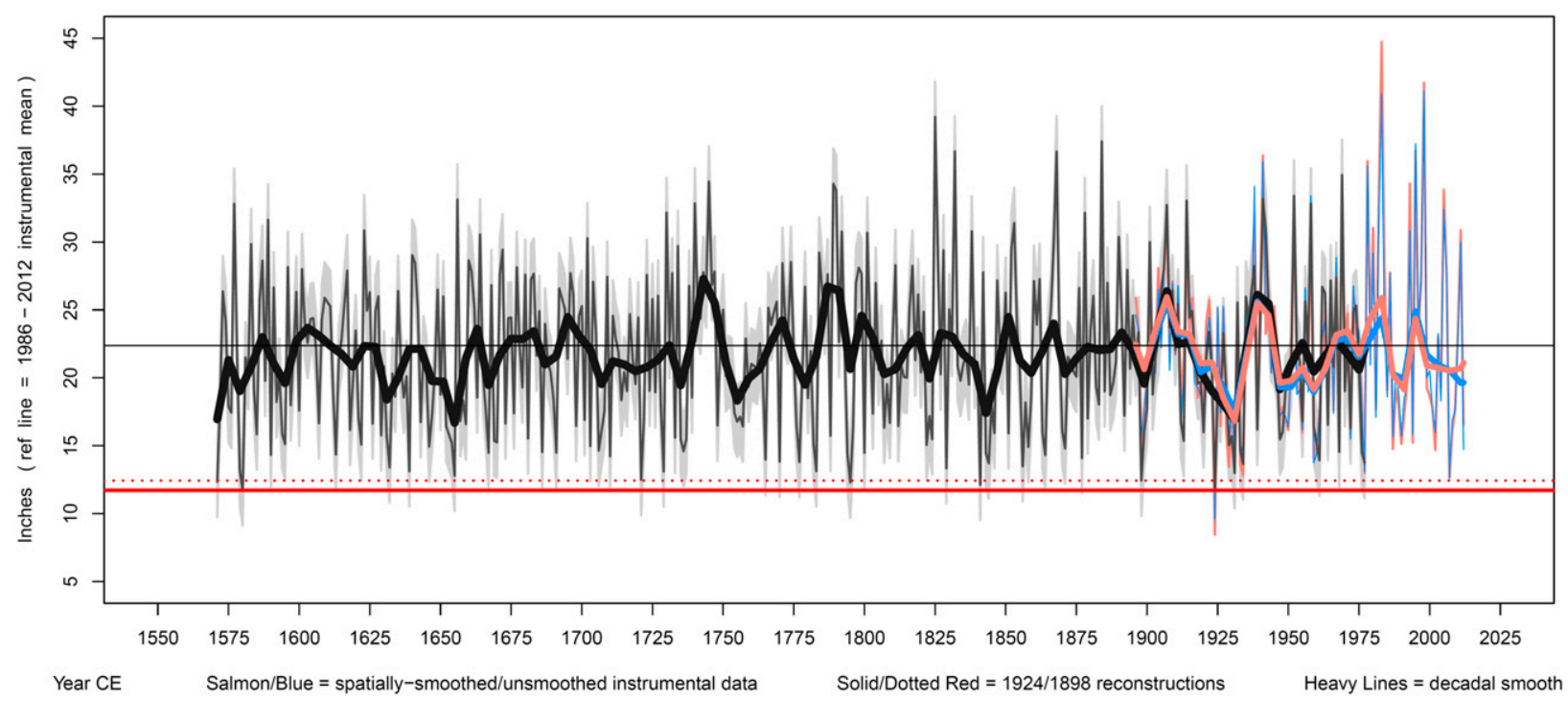

FIG. 9. Time series of reconstructed WY precipitation anomalies (1571-1977: gray lines) for California and western Nevada region (cf. Figs. 5 and 6), together with the observed precipitation record (salmon- and blue-colored lines). The salmon-colored time series is spatially smoothed to the same number of EOFs retained in reconstruction; the blue time series is not spatially smoothed. Light gray shading shows \pm 1 reconstruction RMSE relative to the salmon-colored time series over combined calibration (1916-77) and validation (1896-1915) periods. Calibration and validation statistics are listed in section 2.

precipitation for the western United States for these four extreme years are shown in Fig. 5. Clearly, pronounced precipitation deficits are experienced throughout much of the western United States, which in some cases become most severe on the U.S. West Coast (cf. the maps in Fig. 5 with the observed patterns shown in Fig. 3). It should be noted in this comparison that reconstruction skill is highest in the CANV subregion, in conformance with the skill statistics reported in section 2 and the very high spatial pattern congruences for extreme years discussed below (Fig. S5 of the supplemental material). Analogs to the far west instrumental record droughts prior to the late 1800 s are shown in Fig. 6 (for WYs 1571, 1580, 1795, and 1841; cf. Fig. 9). Again, it can be seen that the spatial pattern of these events is roughly similar to those experienced in the modern record, especially along the U.S. West Coast, suggesting the same strong pressure ridging associated with the instrumental droughts was also present during those years. This suggestion is supported by separate reconstructions of winter [December-February (DJF)] sea level pressure for western North America and the northeastern Pacific Ocean, using the North American Drought Atlas (NADA) (Cook et al. 2004, and updates) and regional late winter [February-March (FM)] temperature reconstructions (Wahl et al. 2014) to drive selection of analog climate states from the PMIP phase 3 (PMIP3) last millennium transient model run of the Max Planck Institute (E. Zorita and E. Wahl 2015, unpublished manuscript). The corresponding maps of DJF sea level pressure (SLP) from these reconstructions are shown in Fig. 7. The relative position of these preinstrumental droughts with respect to the frequency distribution of the reconstructed CANV WY anomalies is shown in the histogram in Fig. 8. Along with 1924, these events comprise the driest approximate $1 \%$ of reconstructed years for CANV in the past half millennium (Table 1; cf. Fig. 9).

Table 1 lists the driest 10 years in California and western Nevada (west of $116.5^{\circ} \mathrm{W}$ ), as reconstructed from the proxy records, and gives their comparative ranks (out of 407 reconstructed years, 1571-1977). Note that the reconstructed average for the $1977 \mathrm{WY}$ for this domain, while quite dry, is not ranked as extreme as other years, and represents a random small undershoot in relation to the instrumental target (cf. Fig. 9). In Figure 9 we show the full time series of precipitation reconstructions for the CANV region: the area marked by a rectangle in Figs. 1, 5, and 6. The spatial pattern congruences between the reconstructed WY precipitation and the overlapping observed CANV values $(1896-1977)$ are generally high $($ median $=0.86)($ Fig. S5; note that 15 out of the 82 possible comparisons are $<0.6$ and that 7 comparisons are $<0.0$ ). Pattern congruence is particularly strong for the most extreme dry and wet years, averaging 0.97 for the four years shown in Fig. 5 and rounding to 1.0 for WY 1969, the wettest reconstructed year during the observed period (Fig. 9).

Overall, 2014 is comparable in amplitude to the CANV dryness reconstructed for WYs 1580, 1924, and 
TABLE 2. Ranking of reconstructed total WY precipitation for driest three consecutive water years for the CANV region for the period 1571-1977. Associated year (CE) value is the central year of the three years, and those occurring during the period of instrumental records (since 1895) are in boldface. For comparison, the rank of other significantly dry three consecutive years (in the top 20) during the instrumental period is also shown. The years 1975-77 are ranked 17th in this reconstruction. The equivalent 3-yr total precipitation and comparative rank in the instrumental record is shown in the fourth column. The average 3-yr total precipitation over the period (1896-2012) for the region is 67.14 in. ( $1 \mathrm{in.} \approx$ $2.54 \mathrm{~cm}$ ); italic values in columns 2 and 3 denote years for which the cumulative 3 -yr precipitation deficit exceeds one year's mean total (22.38 in.). The current 3 -yr period's comparable total is shown for the west region (California and Nevada) as defined by NCDC, because the gridded precipitation totals through September 2014 were not available.

\begin{tabular}{clcc}
\hline \hline Rank & $\begin{array}{l}\text { Year } \\
(\mathrm{CE})\end{array}$ & $\begin{array}{c}\text { Reconstructed } \\
\text { 3-yr total (in.) }\end{array}$ & $\begin{array}{c}\text { Observed } \\
\text { 3-yr total (in.) }\end{array}$ \\
\hline 1 & 1795 & 42.96 & - \\
2 & $\mathbf{1 9 3 0}$ & $\mathbf{4 3 . 7 3}$ & $\mathbf{4 6 . 0 0}$ \\
3 & 1654 & 43.83 & - \\
4 & $\mathbf{1 9 6 0}$ & $\mathbf{4 5 . 4 7}$ & $\mathbf{4 6 . 6 0}$ \\
5 & 1736 & 45.54 & - \\
6 & 1844 & 46.16 & - \\
7 & $\mathbf{1 8 9 9}$ & $\mathbf{4 6 . 2 0}$ & $\mathbf{5 2 . 0 0}$ \\
8 & 1580 & 46.37 & - \\
9 & 1857 & 46.59 & - \\
10 & 1579 & 46.77 & - \\
15 & $\mathbf{1 9 2 5}$ & $\mathbf{4 8 . 3 5}$ & $\mathbf{4 9 . 9 7}$ \\
17 & $\mathbf{1 9 7 6}$ & $\mathbf{4 9 . 0 2}$ & $\mathbf{5 4 . 6 7}$ \\
20 & $\mathbf{1 9 2 9}$ & $\mathbf{5 0 . 0 1}$ & $\mathbf{4 7 . 3 4}$ \\
- & $\mathbf{2 0 1 3}$ & - & $\mathbf{4 5 . 3 4}$ \\
\hline
\end{tabular}

1841 plus similarly dry years in $1795,1571,1898,1721$, 1655, and 1931 (Figs. 5, 6, and 9 and Table 1), suggesting events of this magnitude occur on an approximately 50 -yr average time scale, and thus 2014 is clearly not unprecedented in relation to the past 440 years. We note that the 1923/24 dry episode occurred after an otherwise wet interval characteristic of the early twentieth century in the west region and near the start of a strong decadallength dry period in California (and indeed throughout much of the west region) during the 1930s (Fig. 9). From an extended multiyear perspective, the cumulative precipitation deficit to date for the last three seasons (2012-14) exceeding one year's mean total in California is again similar to reconstructed extreme events but not unprecedented (Table 2). This depth of extended dryness over three straight years occurs three times in the reconstructed CANV time series, centered on WY 1654, 1795, and 1930 (cf. Figs. 9 and 1, bottom; note that the 1930-centered cumulative deficit is slightly below this threshold in the instrumental data as is the comparable CANV total for the current three years; cf. Table 2). Evaluation of running precipitation deficit extremes over 2-50-yr periods is shown in Fig. 10, indicating the largest positive departures from a declining exponential model (as period length increases) for the shortest 2-4-yr periods. The tendency for relatively short intense droughts in CANV to end within about a half decade is likely due to the recurrent nature of El Niño events (Dettinger et al. 1998) and the recurrent nature of socalled atmospheric rivers (Dettinger 2013). We note the difference of these results over the past half millennium compared to the multidecadal drought conditions that occurred in California during medieval times (Graham and Hughes 2007; Stine 1994).

Very warm temperatures accompanied the current exceptional drought in the west region, particularly in California, over the last two WYs, as illustrated in Fig. 11. The combination of very low precipitation and high temperature resulted in extreme moisture deficits as shown in the bottom panel of Fig. 11 in terms of a standardized precipitation-evaporation index (VicenteSerrano et al. 2010). The combination of dry and hot conditions throughout the $2014 \mathrm{WY}$ is reflected in the fact that, as of this writing, nearly $60 \%$ of California was classified as in exceptional drought (Fig. 12).

A widely used drought index is the Palmer drought severity index, which has been reconstructed back to 1000 CE by (Cook et al. 2004, 2014) into the NADA. We compared our reconstructions with the corresponding summer PDSI anomaly maps from the NADA (Fig. 13) for the four WYs shown in Fig. 6. As can be seen by comparing Figs. 6 and 13, the correspondence in the spatial features of these exceptional drought years is generally strong. Although both types of reconstructions rely fundamentally on the basic network of moisture sensitive trees in the west region, the predictor and predictand variables are not the same, and a significant number of predictors used in the NADA are not included in the more spatially restricted streamflow reconstructions used to drive our precipitation reconstructions.

We note that another recent study of the ongoing California drought by Griffin and Anchukaitis (2014) using the June-July PDSI reconstruction from the NADA dataset, which implicitly incorporates the effect of surface temperature in the water balance calculation, found that for the period since the late 1200s CE the central California (state climate divisions 4-7) 2014 PDSI value was the lowest in that reconstruction. The authors also found that, both in the historical instrumental record as well as in a direct precipitation reconstruction for the same region for the months October-June, the 2014 value was unusually low but also likely to have occurred in other years during their study period. Furthermore, some of the more specific details of the Griffin and Anchukaitis reconstruction 


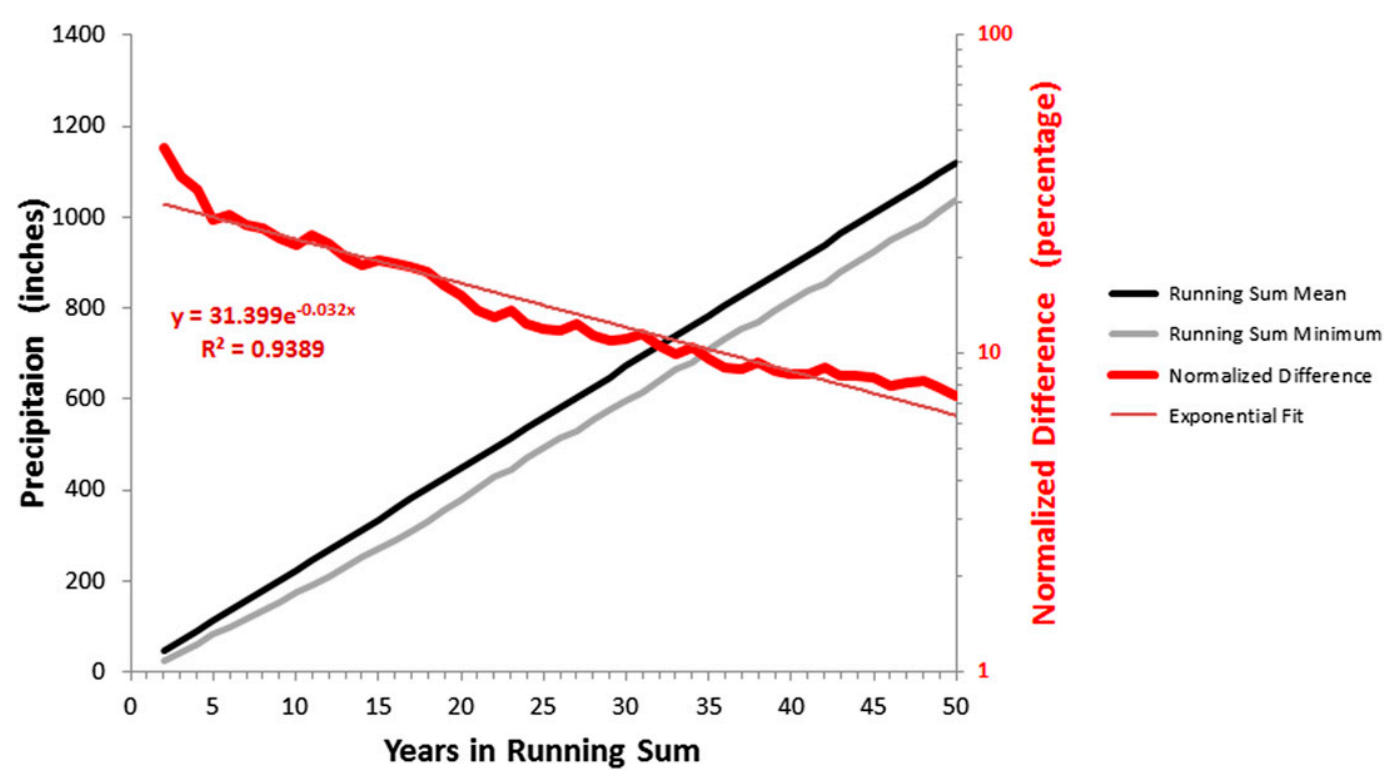

FIG. 10. Running water year precipitation deficit extremes for the California-western Nevada region (cf. Figs. 5 and 6), over 2-50-yr periods. The black curve shows total precipitation for running sums 2-50 yr in length based on using the 1896-2012 mean of approximately $22.38 \mathrm{in}$. $\mathrm{yr}^{-1}\left(1 \mathrm{in} . \mathrm{yr}^{-1} \approx 2.54 \mathrm{~cm} \mathrm{yr}^{-1}\right)$; the gray curve shows corresponding total precipitation for each length of running sum based on the minimum of all possible running sums for a given length over the 1571-1977 reconstruction period (cf. Fig. 9); the thick red curve shows difference between the mean (black) and minimum (gray) values for each length of running sum normalized as a percentage of the mean precipitation sum; and the thin dark red curve shows an exponential fit to the normalized differences, which is linear in the right-hand logarithmic scale, representing a uniform exponential decline in the normalized meanminimum difference. Black and gray values are scaled using the left-hand (linear) axis, and red values are scaled using the right-hand (logarithmic) axis.

cohere well with those presented here; for example, their histogram of anomalies (Fig. 2b) and ours (Fig. 8) are both skewed with a long tail for the wet extremes, and their evaluation of length of duration (Fig. 3b) appears to correspond generally well with our estimates (see Fig. S4 of the supplemental material).

These two studies act as nearly independent confirmation of each other, in the sense that the spatial reconstruction methodology used here contrasts with the single time series method of Griffin and Anchukaitis (2014), and the overlap of tree-ring chronologies incorporated in the two studies is limited to one of the 14 streamflow reconstructions used as predictors here (Salinas River; cf. supplemental material and section 1).

\section{Concluding remarks}

The presence of anomalous ridging in the middle troposphere over and/or upstream from the west coast of North America in extreme dry years is a characteristic atmospheric feature during such years, as numerous previous studies have shown (Cayan and Peterson 1989; Cayan et al. 1998), and would be expected to be present prior to the instrumental record. The fact that the strongest reconstructed dry WYs prior to the observational period (Fig. 6) are spatially similar to observed extreme events that are associated with anomalous ridging (Figs. 2 and 4) supports this expectation, as do separate reconstructions of winter sea level pressure (SLP) during these extreme years (Fig. 7). The latest studies of possible climate changes in the west region as a result of global warming from about the midtwenty-first century onward for the higher scenarios of atmospheric greenhouse gas concentrations project greater aridity in the much of the west region, particularly south of approximately $40^{\circ} \mathrm{N}$ (Garfin et al. 2013; Wang et al. 2014). However, studies by Funk et al. (2014) and Wang and Schubert (2014) do not point to a discernible influence of global warming in the recent U.S. West Coast drought, although Swain et al. (2014) conclude there appears to be a connection to changes in the large-scale atmospheric circulation that favors the occurrence of dry conditions in the west region.

We noted above that the extremely dry WY of 1924 occurred after an extended period of wetter than average conditions (Cook et al. 2011), in contrast to the recent dry spell, which can be considered to have started around the year 2000 (see Fig. 1, bottom). 

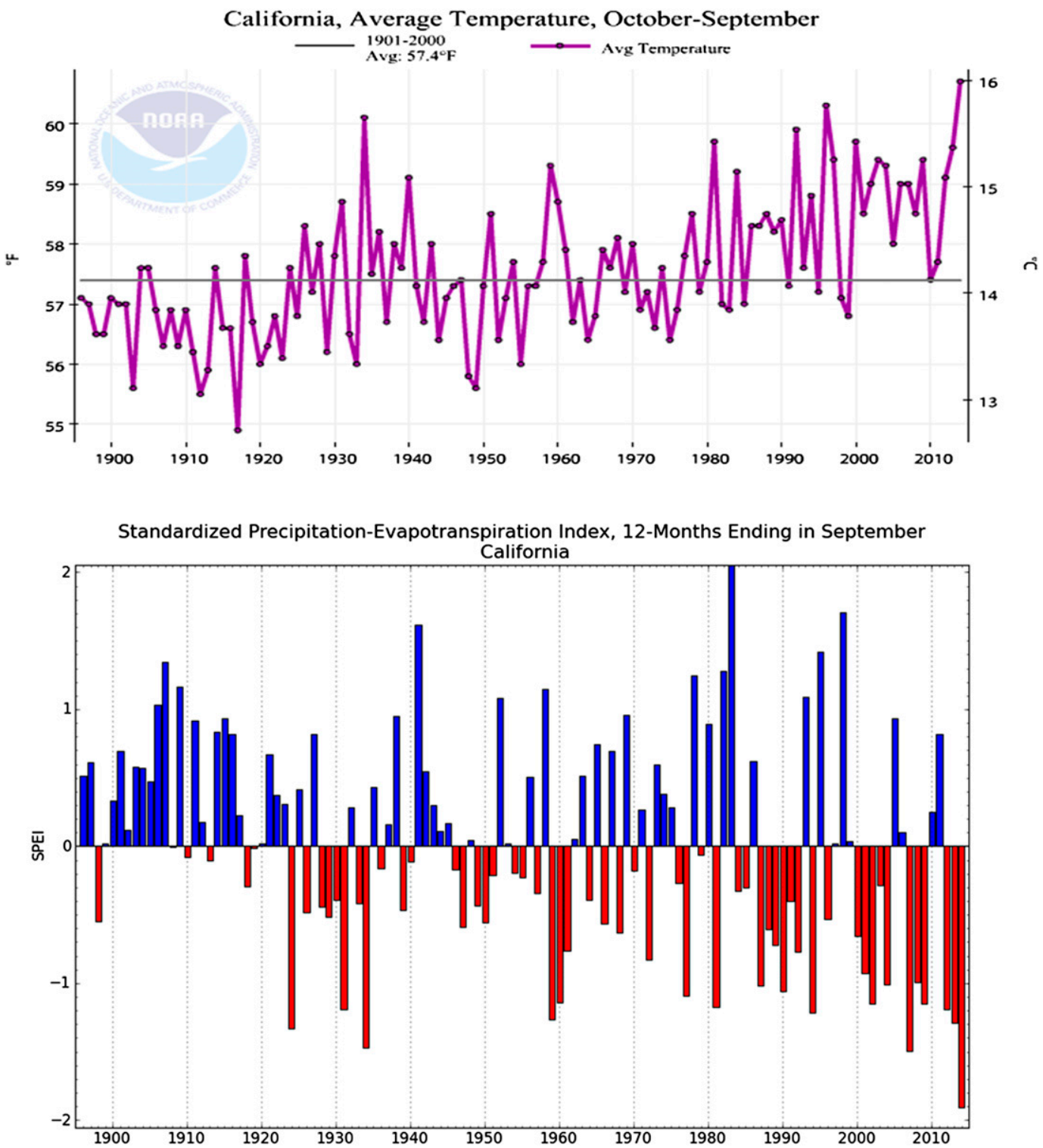

Data Source: WRCC/UI, Created: 10-17-2014

FIG. 11. (top) October-September mean temperature for California from 1895/96 to 2013/14. Data are from the NCEI (Vose et al. 2014). (bottom) Standardized precipitation-evapotranspiration index (Vicente-Serrano et al. 2010) downloaded from the Western Regional Climate Center website (http://www.wrcc.dri.edu/).

Figure S6 of the supplemental material gives an indication of the mean anomalous circulation during the early twentieth-century western pluvial period, suggesting the presence of enhanced westerlies for the November through March season with perhaps more frequent and/or intense rainfall. In contrast, the anomalous circulation in the 13 years preceding the occurrence of the current prolonged drought in the U.S. Southwest (Fig. S6) is characterized by weaker westerlies along the U.S. West Coast with anticyclonic curvature upstream (Luce et al. 2013), which appears to be consistent with the conclusion of Swain et al. (2014).

A number of studies have concluded that the southwestern United States is at risk of significant drying in the future because of greenhouse warming, from a combination of changes in the winter season storm tracks linked to changes in the structure of tropospheric Rossby waves and associated shifts in the mean jet stream position and storm tracks (Neelin et al. 2013; 
California drought status as of September 30, 2014

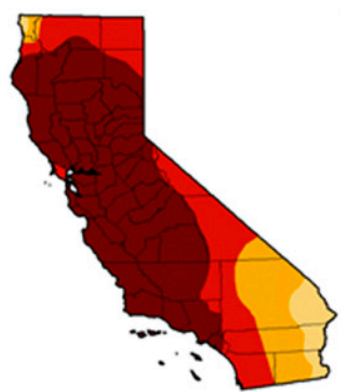

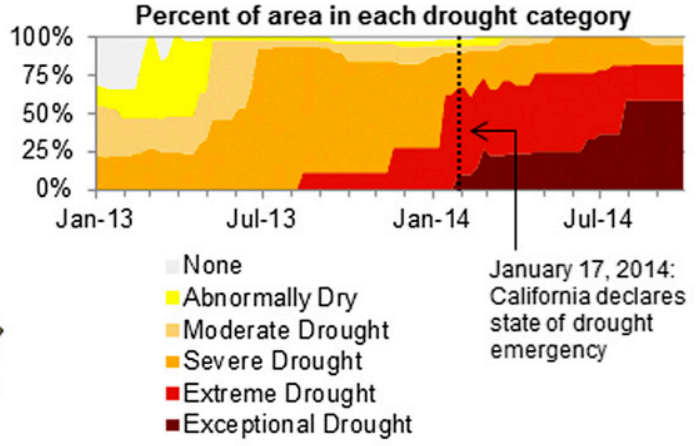

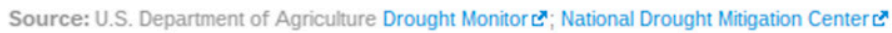

CREOIT: EIAGOV

FIG. 12. (left) Drought map for California as of 30 Sep 2014 and (right) evolution of drought severity over the last approximately 2 years.

Seager et al. 2013). Wang et al. (2014) suggest that the intensity of the winter ridge may be traceable to anthropogenic warming through its effect on ENSO precursor conditions (see also Swain et al. 2014).
Nevertheless, detection and attribution of a climate change signal in the west region (e.g., Seager et al. 2014) over the near term will be made difficult by the high hydrologic variability, as documented in both the
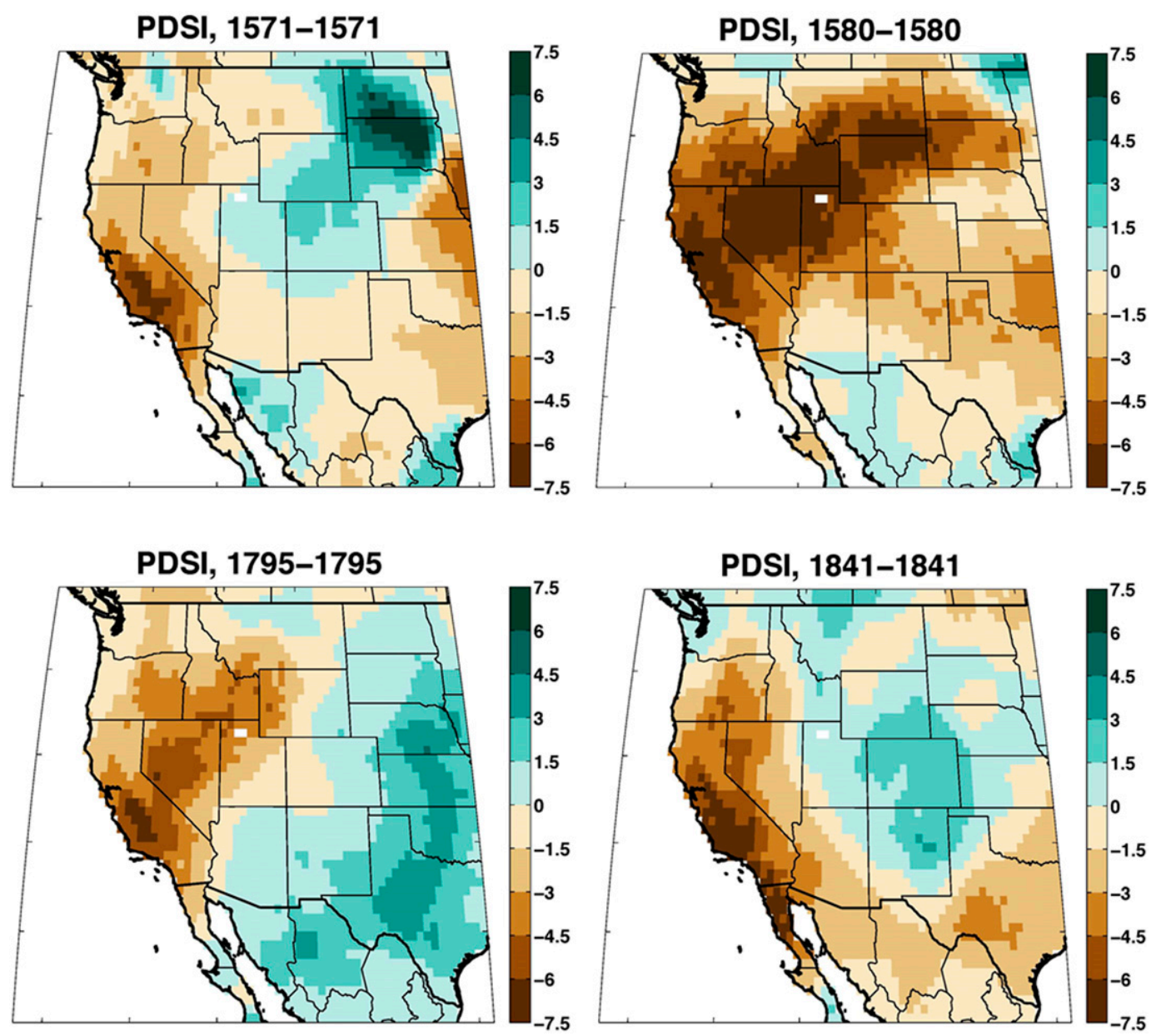

FIG. 13. Reconstructed summer PDSI from the NADA files (Cook et al. 2014) for the same reconstructed drought years depicted in Fig. 6. (Maps kindly provided by Ed and Ben Cook.) 
instrumental and proxy climate records (Dettinger et al. 1998; Hidalgo et al. 2009; Hughes and Brown 1992; Woodhouse et al. 2010; Wise and Dannenberg 2014; this article), although the projected increases in surface temperature will enhance any naturally occurring tendency for drought initiation driven by precipitation deficits (Cayan et al. 2010; cf. Fig. 11; Griffin and Anchukaitis 2014; Cook et al. 2015).

Acknowledgments. Upon publication the reconstruction data will be available through NOAA/PaleoclimatologyWDC for Paleoclimatology (www.ncdc.noaa.gov/dataaccess/paleoclimatology-data). The authors gratefully acknowledge the help of Jeffrey Lukas in evaluating the streamflow reconstructions for use as predictors for spatial precipitation reconstruction, the help of Dr. Eduardo Zorita in preparation of the results shown in Fig. 7, and the help of Dr. Edward Cook in analyzing the reconstructions and providing Fig. 13.

\section{REFERENCES}

Bunde, A., U. Büntgen, J. Ludescher, J. Luterbacher, and H. von Storch, 2013: Is there memory in precipitation? Nat. Climate Change, 3, 174-175, doi:10.1038/nclimate1830.

Cayan, D. R., and D. H. Peterson, 1989: The influence of atmospheric circulation on streamflow in the West. Aspects of Climate Variability in the Pacific and the Western Americas, Geophys. Monogr., Vol. 55, Amer. Geophys. Union, 375-397.

—_, M. D. Dettinger, H. F. Diaz, and N. E. Graham, 1998: Decadal variability of precipitation over western North America. J. Climate, 11, 3148-3166, doi:10.1175/ 1520-0442(1998)011<3148:DVOPOW > 2.0.CO;2.

- T. Das, D. W. Pierce, T. P. Barnett, M. Tyree, and A. Gershunov, 2010: Future dryness in the southwest US and the hydrology of the early 21 st century drought. Proc. Natl. Acad. Sci. USA, 107, 21 271-21 276, doi:10.1073/pnas.0912391107.

Compo, G., and Coauthors, 2011: The Twentieth Century Reanalysis Project. Quart. J. Roy. Meteor. Soc., 137, 1-28, doi:10.1002/qj.776.

Cook, B. I., R. Seager, and R. L. Miller, 2011: On the causes and dynamics of the early twentieth-century North American pluvial. J. Climate, 24, 5043-5060, doi:10.1175/ 2011JCLI4201.1.

_ , J. E. Smerdon, R. Seager, and E. R. Cook, 2014: Pancontinental droughts in North America over the last millennium. J. Climate, 27, 383-397, doi:10.1175/JCLI-D-13-00100.1.

_, T. R. Ault, and J. E. Smerdon, 2015: Unprecedented 21st-century drought risk in the American Southwest and central plains. Sci. Adv., 1, doi:10.1126/sciadv.1400082.

Cook, E. R., C. A. Woodhouse, C. M. Eakin, D. M. Meko, and D. W. Stahle, 2004: Long-term aridity changes in the western United States. Science, 306, 1015-1018, doi:10.1126/ science. 1102586 .

Dettinger, M. D., 2013: Atmospheric rivers as drought busters on the U.S. West Coast. J. Hydrometeor., 14, 1721-1732, doi:10.1175/JHM-D-13-02.1.

_ D. R. Cayan, H. F. Diaz, and D. M. Meko, 1998: North-south precipitation patterns in western North America on interannual-to-decadal timescales. J. Climate, 11, 3095-3111, doi:10.1175/1520-0442(1998)011<3095:NSPPIW>2.0.CO;2.

Funk, C., A. Hoell, and D. Stone, 2014: Examining the contribution of the observed global warming trend to the California droughts of 2012/13 and 2013/14 [in "Explaining Extreme Events of 2013 from a Climate Perspective"]. Bull. Amer. Meteor. Soc., 95 (9), S11-S15.

Garfin, G., A. Jardine, R. Merideth, M. Black, and S. LeRoy, Eds., 2013: Assessment of climate change in the southwest United States: A report prepared for the National Climate Assessment. Southwest Climate Alliance Rep., 531 pp.

Graham, N. E., and M. K. Hughes, 2007: Reconstructing the mediaeval low stands of Mono Lake, Sierra Nevada, California, USA. Holocene, 17, 1197-1210, doi:10.1177/ 0959683607085126.

Griffin, D., and K. J. Anchukaitis, 2014: How unusual is the 20122014 California drought? Geophys. Res. Lett., 41, 9017-9023, doi:10.1002/2014GL062433.

Hidalgo, H. G., and Coauthors, 2009: Detection and attribution of streamflow timing changes to climate change in the western United States. J. Climate, 22, 3838-3855, doi:10.1175/ 2009JCLI2470.1.

Hughes, M. K., and P. M. Brown, 1992: Drought frequency in central California since 101 B.C. recorded in Giant Sequoia tree rings. Climate Dyn., 6, 161-167, doi:10.1007/BF00193528.

Luce, C. H., J. T. Abatzoglu, and Z. A. Holden, 2013: The missing mountain water: Slower westerlies decrease orographic enhancement in the Pacific Northwest USA. Science, 342, 1360 1364, doi:10.1126/science.1242335.

Namias, J., 1978: Multiple causes of the North American abnormal winter 1976-77. Mon. Wea. Rev., 106, 279-295, doi:10.1175/ 1520-0493(1978)106<0279:MCOTNA > 2.0.CO;2.

Neelin, J. D., B. Langenbrunner, J. E. Myerson, A. Hall, and N. Berg, 2013: California winter precipitation change under global warming in the Coupled Model Intercomparison Project phase 5 ensemble. J. Climate, 26, 6238-6256, doi:10.1175/ JCLI-D-12-00514.1.

Seager, R., M. Ting, C. Li, N. Naik, B. Cook, J. Nakamura, and H. Liu, 2013: Projections of declining surface-water availability for the southwestern United States. Nat. Climate Change, 3, 482-486, doi:10.1038/nclimate1787.

—, M. Hoerling, S. Schubert, H. Wang, B. Lyon, A. Kumar, J. Nakamura, and N. Henderon, 2014: Causes and predictability of the 2011 to 2014 California drought. NOAA Drought Task Force Assessment Rep., 42 pp. [Available online at http://cpo.noaa.gov/sites/cpo/MAPP/Task\%20Forces/ DTF/californiadrought/california_drought_report.pdf.]

Stine, S., 1994: Extreme and persistent drought in California and Patagonia during mediaeval time. Nature, 369, 546-549, doi:10.1038/369546a0.

Swain, D. L., M. Tsiang, M. Haugen, D. Singh, A. Charland, B. Rajaratnam, and N. S. Diffenbaugh, 2014: The extraordinary California drought of 2013/2014: Character, context, and the role of climate change [in "Explaining Extreme Events of 2013 from a Climate Perspective"]. Bull. Amer. Meteor. Soc., 95 (9), S3-S7.

Vicente-Serrano, S. M., S. Beguería, and J. I. López-Moreno, 2010: A multiscalar drought index sensitive to global warming: The standardized precipitation evapotranspiration index. J. Climate, 23, 1696-1718, doi:10.1175/2009JCLI2909.1.

Vose, R. S., and Coauthors, 2014: Improved historical temperature and precipitation time series for U.S. climate divisions. J. Appl. Meteor. Climatol., 53, 1232-1251, doi:10.1175/ JAMC-D-13-0248.1 
Wahl, E. R., and J. E. Smerdon, 2012: Comparative performance of paleoclimate field and index reconstructions derived from climate proxies and noise-only predictors. Geophys. Res. Lett., 39, L06703, doi:10.1029/2012GL051086.

Wang, H., and S. Schubert, 2014: Causes of the extreme dry conditions over California during early 2013 [in "Explaining Extreme Events of 2013 from a Climate Perspective"']. Bull. Amer. Meteor. Soc., 95 (9), S7-S11.

Wang, S.-Y. S., L. Hipps, R. R. Giles, and J.-H. Yoon, 2014: Probable causes of the abnormal ridge accompanying the 201314 California drought: ENSO precursor and anthropogenic warming footprint. Geophys. Res. Lett., 41, 3220-3226, doi:10.1002/2014GL059748.

Wilks, D. S., 1995: Statistical Methods in the Atmospheric Sciences. Academic Press, 467 pp.

Wise, E. K., and M. P. Dannenberg, 2014: Persistence of pressure patterns over North America and the North Pacific since AD 1500. Nat. Commun., 5, 4912, doi:10.1038/ncomms5912.

Woodhouse, C. A., D. M. Meko, G. M. MacDonald, D. W. Stahle, and E. R. Cook, 2010: A 1,200-year perspective of 21st century drought in southwestern North America. Proc. Natl. Acad. Sci. USA, 107, 21 283-21 288, doi:10.1073/pnas.0911197107. 